\title{
Deprescribing for older patients
}

\author{
Christopher Frank MD, Erica Weir MD MSc
}

See related editorial at www.cmaj.ca/lookup/doi:10.1503/cmaj.122099 and articles at www.cmaj.ca/lookup/doi:10.1503/cmaj.122012 and www.cmaj.ca/lookup/doi:10.1503/cmaj.130523

$\mathrm{T}$ he principles that guide optimal prescribing for older patients ${ }^{1,2}$ (Box 1) include deprescribing medications that are no longer indicated, appropriate or aligned with evolving goals of care. Deprescribing is a relatively new term that focuses attention on the sometimes overlooked step in medication review of stopping medications to improve outcomes and decrease risks associated with polypharmacy in older people. ${ }^{3-5}$ These risks include nonadherence, ${ }^{6}$ adverse drug reactions, ${ }^{7}$ functional and cognitive decline, ${ }^{8}$ and falls. ${ }^{9}, 10$ In Canada, more than $50 \%$ of older people living in long-term care facilities and $27 \%$ of those living in the community take more than five medications a day. ${ }^{11}$ Although frailty ${ }^{12}$ should be a catalyst for deprescribing, the principles and practice of deprescribing apply to all older patients and, if integrated early into care, may play a role in preventing frailty.

In this article, we describe an approach to deprescribing based on principles, practice and available evidence. We reviewed evidence from systematic reviews and randomized controlled trials on the impact of deprescribing (Box 2). Most of the studies failed to measure clinical outcomes relevant to the care of older patients, such as improved functioning. The quality of the evidence was limited by small samples, short study durations and heterogeneous study designs. ${ }^{13-15}$ Nonetheless, we found evidence ${ }^{16}$ that a substantial proportion of older patients can tolerate careful dosage reduction or withdrawal of certain classes of medications without harmful consequences and with possible improvement in quality of life, especially if the goals of care shift from diseasespecific targets to improvements in symptom management and function.

\section{When and for whom is deprescribing appropriate?}

Although all older people taking prescribed drugs may benefit from a medication review with a deprescribing lens, those who are frail ${ }^{12}$ are the main target of this approach. Frail patients tend to take more medications and have more adverse outcomes related to medications than other older patients. They are also more likely to have limited life expectancy than well older people of similar age. ${ }^{17}$ Medication lists tend to lengthen as patients age, and there are few guidelines to inform medication management in the context of polypharmacy, multiple morbidities and age-related changes to pharmacokinetics and pharmacodynamics (Box 1). All prescribers contributing to the medication list need to be alert to "prescribing inertia"18 (the tendency to automatically renew a medication even when the original indication is no longer present) and should view polypharmacy as an impetus to deprescribe when appropriate.

Any patient interaction can be an opportunity for critical medication review. Certain transitional events in the care of older patients provide identifiable opportunities. For example, medication errors tend to occur during transfers between care settings. ${ }^{19,20}$ To reduce this risk, facilities routinely undertake systematic reconciliations of medication lists between sites; this is an opportunity for deprescribing. Similarly, changes in the overall health of a patient that affect life expectancy, such as the diagnosis of a terminal cancer or progression of dementia or clinical frailty, ${ }^{17}$ signal the need for medication review to identify drugs that are unlikely to provide meaningful benefit to the individual in their remaining time. ${ }^{21}$

\section{Can deprescribing medications improve clinical outcomes?}

It is well recognized that medications can cause harm in older patients, and there is growing rec-
Competing interests: None declared.

This article has been peer reviewed.

Correspondence to: Christopher Frank, frankc @ providencecare.ca

CMAJ 2014. DOI:10.1503 /cmaj.131873 
ognition that careful adherence to disease-specific guidelines in frail patients can result in increased risks of drug interactions and adverse reactions. ${ }^{22}$

Despite this context, the evidence to support deprescribing as a broad strategy to improve clinical outcomes in older patients is weak. According to three recent reviews, ${ }^{13-15}$ most of the trials studying deprescribing failed to measure clinical outcomes relevant to the care of older patients, such as improved functioning, and were limited by small samples and short study durations. Although many of the interventions involved pharmacists, the engagement between the pharmacist and prescriber was not adequately described ${ }^{14}$ and few studies incorporated patient perspectives. Heterogeneity in study design, sample selection, choice of outcome measure and intervention made it difficult to synthesize results and draw conclusions.

Nonetheless, when the evidence about deprescribing is organized by the intentions to stop drugs that are no longer indicated, that are no longer appropriate or that no longer align with goals of care, deprescribing appears to be potentially helpful without causing substantial harm, if done well.

\section{Box 1: Principles to guide prescribing and deprescribing} medications in older patients ${ }^{1,2}$

Pharmacokinetics: what the body does to the drug; what factors determine the concentration of the drug at the target receptor or organ

Absorption: little change due to aging alone, but it can be affected by medications and conditions common in older people

Distribution: increased fat:water ratio with aging; protein binding may be affected by malnutrition or medical conditions

Metabolism/excretion: decrease in some liver metabolism with aging may affect different drugs differently; decrease in renal excretion with aging may affect drugs dependent on kidneys for excretion

Pharmacodynamics: what the drug does to the body; what factors affect whether medication will have a greater or lesser affect with same serum concentration

\section{Prescribing tips}

- Remember that medications may cause illness

- Know the patient and his or her current medications (and how they are taken)

- Consider nonpharmacologic therapy

- Know the pharmacology of the prescribed drugs

- Keep drug regimens simple

- Establish treatment goals at the time of prescription

- Strive for a diagnosis before prescribing; if a therapeutic trial is done, stop medications if treatment goals are not reached

- Encourage the patient to be a responsible medication user and to participate in his or her medication management

- Consider the patient's current medications and medical conditions before adding or changing new medications

- Start low, go slow (but get there!)

- Monitor closely for adverse effects when starting or stopping medications

- Manage the whole of the patient's treatment regimen

\section{Drugs that are no longer indicated}

A systematic review of 31 trials involving older adults, published in 2007, examined the benefits and harms of withdrawing medications felt to be no longer indicated. ${ }^{16}$ The studies focused on the complete withdrawal of one of four classes (benzodiazepines, antihypertensives, diuretics for indications other than heart failure and antipsychotics). Although the included studies were limited by small samples and short durations, the results showed that a substantial proportion of participants could tolerate withdrawal of one of these classes and experienced benefits of reduced risk of falling (e.g., psychotropic medication withdrawal, hazard ratio $0.34,95 \%$ confidence interval $0.16-0.74)^{23}$ and improvement in total memory test scores (e.g., benzodiazepine withdrawal, $p<0.004){ }^{24}$

These results are borne out in current clinical practice. It is almost conventional wisdom that tapering benzodiazepines ${ }^{25}$ can improve cognition and reduce the risk of falls. The recent changes in clinical practice guidelines to relax targets for blood pressure (e.g., 150/90 $\mathrm{mm} \mathrm{Hg})^{26,27}$ and blood glucose (hemoglobin $\mathrm{A}_{1 \mathrm{C}}$ concentration $<7.5 \%)^{28}$ in older patients is informed by the trade-off between the risk of vascular events with the risk of falling because of orthostatic hypoten$\operatorname{sion}^{29}$ or hypoglycemia. Likewise, there is evidence that a systematic approach to reduce the prescribing of antipsychotics for behavioural symptoms of dementia when stable allows many people to be off medications for sustained periods of time or indefinitely. ${ }^{30}$

\section{Drugs that are no longer appropriate}

A recent Cochrane review ${ }^{31}$ concluded that systematic medication reviews involving a pharmacist working closely with the physician and the patient or caregiver results in a substantial reduction in inappropriate prescribing, either through medication substitution or discontinuation. The results from these studies do not clarify whether improving appropriateness of prescribing improves clinical outcomes; however, this association may be inferred from the evidence about

\section{Box 2: Evidence for this review}

We included published systematic reviews that were known to us. We then searched the databases Embase and MEDLINE using the terms "deprescribing" and "drug withdrawal" to identify additional systematic reviews as well as reports of randomized controlled trials of deprescribing published from January 2010 to March 2014. We restricted our review to articles published in English that had a study population aged 65 years or more. 
risk of adverse outcomes used to construct tools to identify inappropriate medications in older patients, such as the Beer criteria. ${ }^{32}$

\section{Drugs that no longer align with goals}

Frail patients or their substitute decision-makers may shift treatment goals away from prolonging life to controlling symptoms or maximizing function. Eliciting preferences and perspectives on outcomes and goals of therapy is important to guide decisions to reduce or stop medications. In their work on universal health outcomes, Tinetti and colleagues ${ }^{33}$ found that the proportion of older patients who identified reducing the risk of falls as their priority equalled the proportion who prioritized stroke prevention with use of antihypertensives. Decreasing the dose or stopping an antihypertensive medication may be an acceptable choice for someone who has had frequent falls or has limited function, a poor prognosis or recent hip fracture, even at the cost of increased stroke risk. More studies are needed to assist with these difficult discussions and decisions about preferences and trade-offs.

\section{What are some of the guiding principles and steps involved in deprescribing?}

In the absence of clear evidence about the best approach to deprescribing, a structured stepwise approach is recommended (Figure 1, Table 1). ${ }^{3,4}$ Either a specific clinical concern or a routine medical review may prompt deprescribing. The first step is to ask the patient to bring in all prescribed and over-the-counter medications for a visual "brown bag review" by the physician, nurse or pharmacist. This exercise provides a lot of information about the patient's understanding of and attitudes toward his or her medications and pill-taking habits. The resulting list of current medications should be cross-referenced with the chart and the pharmacy list when possible.
Prepare patient for eventual review of medication at the time of prescription:

- Clarify expectations and outcomes/goals

- Develop time frame/plan for review

- Explain that a change in health status may signal the need for a review
- Ensure medication list is accurate

- Assess patient's adherence to medications

- Cross-reference medications on list with medical indications

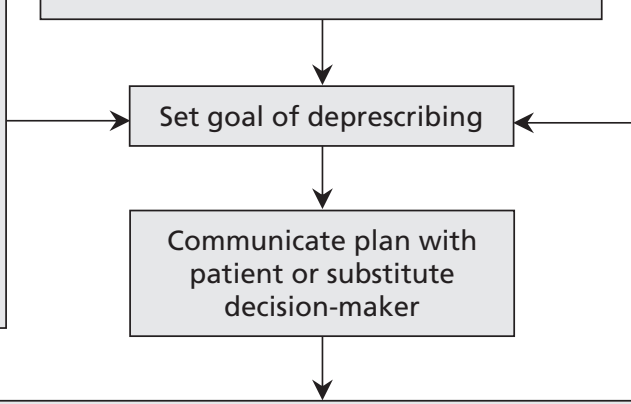

Identify issues related to medications

- Number of medications or uncertainty of indication

- Patient/family concerns

- Adverse effects, such as falls and confusion

- Better options available in specific drug class

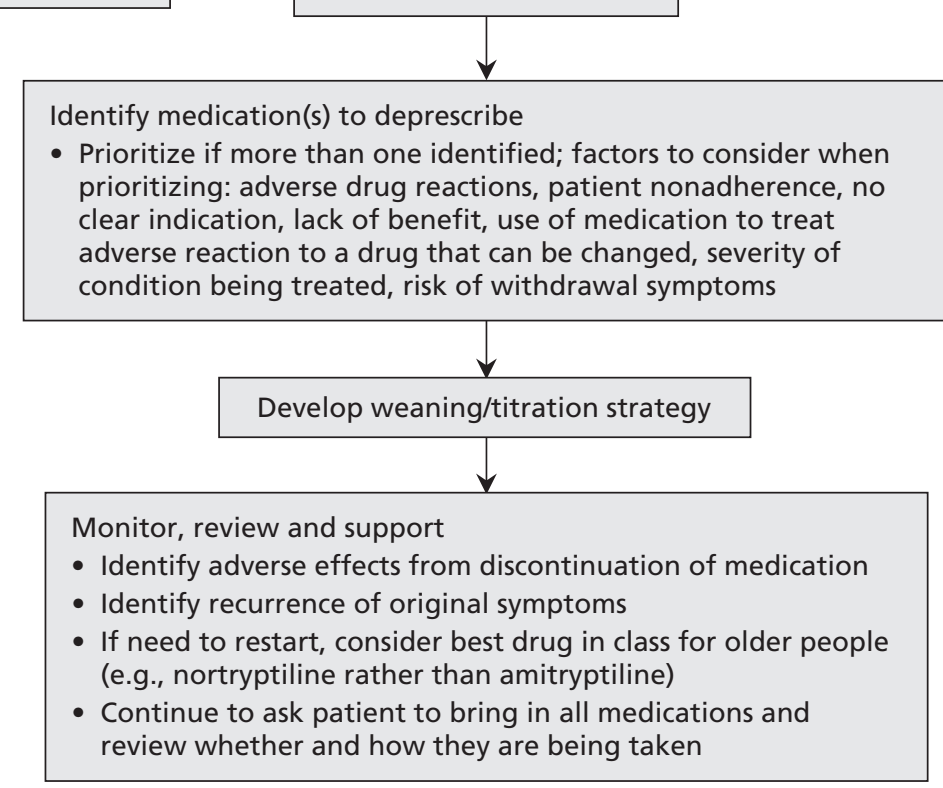

Figure 1: Practical approach to deprescribing. 
Each medication should be classified according to indication. Medications without a current, credible indication and medications duplicated for the same indication are candidates for deprescribing. In addition, the appropriateness of drug choice and dose within each class of medications may be evaluated at this point and modified if required. A number of tools (Table 2) are available to assist with identifying inappropriate medications $^{32,34-40}$ and, occasionally, relevant medications that need to be started..$^{36}$

Often patients will have stopped taking a prescribed medication on their own volition. It is necessary to understand why and to evaluate the justification for continuing with the prescription or not. Medications not being taken regularly are candidates for discontinuation if there are no evident health consequences resulting from the nonadherence.
Current medications should align with current goals of care. With older patients, discussions about goals of care need to be framed in terms of the patient's functional ability, clinical frailty and life expectancy. Predicting life expectancy remains as much the art of medicine as science. According to a recent systematic review of 16 potential prognostic indicators, 10 predicted greater than $50 \%$ mortality, but only 3 predicted greater than $80 \%$ risk in the highest risk group..$^{41}$ Tools focusing on severity of frailty, such as the Clinical Frailty Scale, ${ }^{12,42}$ provide general prognostic information that may help to identify patients with limited life expectancy.

As part of the discussion about goals of care, it is important to clarify the patient's preferences for trade-offs between risk reduction (e.g.,"I want to avoid a stroke at all costs") and symptom management (e.g., "I want help with my pain") or between disease-specific targeted goals (e.g., "Please lower

Table 1: Examples of medications to possibly deprescribe at certain steps of medication review $3,4 *$

Reason to stop medication or decrease dose

Examples

Comment

Noncompliance without negative health effect

- Antihypertensive

- Oral diabetic medication

Taken incorrectly without negative health effect (or without benefit)

Not indicated or relative contraindication

(

No longer indicated

- Puffers: some delivery systems are easier to use by older patients

- Statin for primary prevention

- Docusate not recommend

- Calcium-channel blocker in patient with systolic heart failure
- Identified through careful visual review of medications brought in by the patient and discussion about his or her understanding of and attitudes toward the medications and pill-taking habits

- In some circumstances, use can be corrected by showing patient how to use an aerochamber

- No evidence for benefit in older patients

- Insufficient evidence for benefit to recommend or

\begin{tabular}{|c|c|c|}
\hline \multirow[t]{4}{*}{ No longer indicated } & - Bisphosphonate after $5 \mathrm{yr}$ & $\begin{array}{l}\text { - No evidence of effectiveness after } 5 \mathrm{yr} \text { of continuous } \\
\text { treatment }\end{array}$ \\
\hline & $\begin{array}{l}\text { - Clopidogrel: as per guideline after } \\
\text { cute coronary syndrome }\end{array}$ & $\begin{array}{l}\text { - Treatment often extends beyond guideline } \\
\text { recommendations }\end{array}$ \\
\hline & $\begin{array}{l}\text { - Benzodiazepine } \\
\text { - NSAID } \\
\text { - PPI }\end{array}$ & $\begin{array}{l}\text { - Intended for short-term use but susceptible to } \\
\text { "prescribing inertia" (tendency to automatically } \\
\text { renew a medication even when the original } \\
\text { indication is no longer present) }\end{array}$ \\
\hline & $\begin{array}{l}\text { - Cholinesterase inhibitor (e.g., in } \\
\text { patient with very limited prognosis) }\end{array}$ & - Patient moves to terminal phase of illness \\
\hline \multirow{2}{*}{$\begin{array}{l}\text { Inappropriate choice for } \\
\text { geriatric patient }\end{array}$} & - Digoxin > $125 \mu \mathrm{g} / \mathrm{d}^{34}$ & - Risk of toxicity with age-related decline in renal function \\
\hline & - Amitriptyline $\mathrm{e}^{34}$ & - Risk of falls and fractures \\
\hline \multirow[t]{2}{*}{$\begin{array}{l}\text { No longer aligns with goals } \\
\text { of care or life expectancy }\end{array}$} & $\begin{array}{l}\text { - Statin in patient with limited life } \\
\text { expectancy }(<5 \mathrm{yr}) \\
\text { - Bisphosphonate in patient with } \\
\text { limited life expectancy }(<2 \mathrm{yr})\end{array}$ & \\
\hline & $\begin{array}{l}\text { - Coumadin: decision requires } \\
\text { discussion with patient about risk- } \\
\text { benefit balance }\end{array}$ & $\begin{array}{l}\text { - No current evidence to guide at what point age- } \\
\text { related risk outweighs benefit; frailty and expected } \\
\text { life expectancy may be more relevant factors }\end{array}$ \\
\hline
\end{tabular}


my blood pressure") and universal goals ("Please keep me as independent as possible"). As goals of care evolve from disease-specific to more universal ones, understanding the relative contribution of chronic conditions to universal outcomes such as self-rated health, functioning, symptom burden and mortality can help to elicit priorities and guide clinical decisions. ${ }^{43}$

Once a decision to deprescribe a drug is made, engaging the patient or caregiver in the plan is important. A number of medications require tapering. Health care providers, patients and care- givers need to monitor for withdrawal-related adverse events (Table 3). ${ }^{44,45}$ In some instances, it may be necessary to restart the medication.

\section{What are some of the challenges and barriers to deprescribing?}

Establishing a successful deprescribing plan takes time and open discussion between the physician and the patient, which does not always occur. Studies on the topic identify several barri-

Table 2: Examples of tools to assist with medication review and deprescribing ${ }^{35}$

\begin{tabular}{|c|c|c|c|}
\hline Tool & Description & Level of evidence & Comments \\
\hline Beers criteria ${ }^{32}$ & $\begin{array}{l}\text { List of drugs of concern in } \\
\text { geriatric care and associated } \\
\text { quality of evidence and } \\
\text { strength of recommendation }\end{array}$ & $\begin{array}{l}\text { Consensus of expert panel } \\
\text { using Delphi technique; } \\
\text { strong link between } \\
\text { medications on the list and } \\
\text { poor patient outcomes } \\
\text { confirmed in studies }\end{array}$ & $\begin{array}{l}\text { Many of the drugs are } \\
\text { older and out of use; } \\
\text { excludes drugs of concern } \\
\text { with insufficient evidence }\end{array}$ \\
\hline STOPP 34 & $\begin{array}{l}\text { Screening tool with } 65 \\
\text { indicators; focuses on } \\
\text { drug-drug and drug-disease } \\
\text { interactions }\end{array}$ & & $\begin{array}{l}\text { Items groups by physiologic } \\
\text { systems and by drug class; } \\
\text { short time to complete }\end{array}$ \\
\hline START ${ }^{36}$ & $\begin{array}{l}\text { Screening tool to identify } \\
\text { possible prescribing omissions }\end{array}$ & & $\begin{array}{l}\text { Similar to STOPP in } \\
\text { structure; it does not relate } \\
\text { to deprescribing but may } \\
\text { help optimize medications }\end{array}$ \\
\hline Anticholinergic risk scale (ARS) ${ }^{37}$ & $\begin{array}{l}\text { Ranked categorical list of } \\
\text { commonly prescribed } \\
\text { medications with } \\
\text { anticholinergic potential }\end{array}$ & $\begin{array}{l}\text { Statistically significant } \\
\text { correlation between higher } \\
\text { ARS scores and increased } \\
\text { risk of anticholinergic } \\
\text { adverse effects }\end{array}$ & $\begin{array}{l}\text { May help identify } \\
\text { medications contributing to } \\
\text { adverse effects such as } \\
\text { confusion, urinary } \\
\text { retention }\end{array}$ \\
\hline ARMOR $^{38}$ & $\begin{array}{l}\text { Algorithm that prompts } \\
\text { review of drug classes, } \\
\text { interactions, functional } \\
\text { status, systems review and } \\
\text { reassess status }\end{array}$ & $\begin{array}{l}\text { Tested in only } 1 \text { nursing } \\
\text { facility }\end{array}$ & $\begin{array}{l}\text { Can be used to assess } \\
\text { medications, initial } \\
\text { assessment, falls or } \\
\text { behavioural disturbance, } \\
\text { and rehabilitation potential }\end{array}$ \\
\hline Geriatric-palliative method ${ }^{39}$ & $\begin{array}{l}\text { Consensus-based flowchart to } \\
\text { reduce polypharmacy }\end{array}$ & $\begin{array}{l}\text { Applied in } 6 \text { geriatric } \\
\text { nursing departments, } \\
\text { (119 patients); significant } \\
\text { reduction in mortality, } \\
\text { hospital admissions and cost }\end{array}$ & \\
\hline Prescribing Optimization Method ${ }^{40}$ & $\begin{array}{l}6 \text { questions to guide general } \\
\text { practitioners to address } \\
\text { under-treatment, adherence, } \\
\text { inappropriate drugs, adverse } \\
\text { drug reactions, interactions } \\
\text { and dosing }\end{array}$ & $\begin{array}{l}\text { Improvement in optimal } \\
\text { prescribing by } 45 \text { physicians } \\
\text { when applied to a patient } \\
\text { case history }\end{array}$ & \\
\hline $\begin{array}{l}\text { Choosing Wisely Canada (www. } \\
\text { choosingwiselycanada.org/ } \\
\text { recommendations/canadian- } \\
\text { geriatrics-society-2/) and Choosing } \\
\text { Wisely (www.choosingwisely.org/ } \\
\text { doctor-patient-lists/american- } \\
\text { geriatrics-society/) }\end{array}$ & $\begin{array}{l}\text { Management } \\
\text { recommendations from the } \\
\text { American and Canadian } \\
\text { Geriatrics Societies }\end{array}$ & $\begin{array}{l}\text { Expert opinion based on } \\
\text { variety of evidence levels }\end{array}$ & $\begin{array}{l}\text { Recommendations may } \\
\text { advise against use of specific } \\
\text { medications in older } \\
\text { patients or advise on } \\
\text { treatment targets that could } \\
\text { facilitate deprescribing } \\
\text { (e.g., hemoglobin } A_{1 c} \text { target } \\
\text { and oral agents) }\end{array}$ \\
\hline
\end{tabular}


ers in attitude and practice to be overcome by both physician and patient.

Schuling and colleagues ${ }^{46}$ conducted focus groups with Dutch general practitioners to explore their feelings about and experiences with deprescribing for very old patients with multiple morbidities. They found that the physicians tended to dichotomize medications into symptomatic and preventive types. Physicians expressed more difficulty about withdrawing preventive medications because of the lack of evidence to inform patients about the specifics of risks and benefits with discontinuation and be- cause of the challenge of discussions about life expectancy and quality of life. The general practitioners also expressed concern about stopping medications prescribed by medical specialists. They identified training in shared decision-making to elicit patient preferences and explicit rules for collaborating with medical specialists as potential ways to help them with deprescribing.

Reeve and colleagues ${ }^{47}$ published a systematic review of 21 studies related to medication cessation and patients' beliefs. Three themes emerged: beliefs about the appropriateness of the medication being deprescribed, concerns about

Table 3: Medications commonly associated with withdrawal-related adverse events ${ }^{44,45}$

\begin{tabular}{|c|c|c|}
\hline Medication & Effect of discontinuation* & $\begin{array}{l}\text { Withdrawal-related } \\
\text { manifestations }\end{array}$ \\
\hline \multicolumn{3}{|c|}{$\begin{array}{l}\text { Increased risk of } \\
\text { discontinuation syndrome }\end{array}$} \\
\hline Antianginal agent & Recurrence & Angina \\
\hline Anticonvulsant & Withdrawal, recurrence & Anxiety, depression, seizures \\
\hline Benzodiazepine & $\begin{array}{l}\text { Withdrawal, rebound, recurrence: } \\
\text { common strategy is to taper by } 10 \% \\
\text { of the dose every } 1-2 \text { wk until the } \\
\text { dose is at } 20 \% \text { of the original dose, } \\
\text { then taper by } 5 \% \text { every } 2-4 \mathrm{wk}\end{array}$ & $\begin{array}{l}\text { Seizures, agitation, anxiety, } \\
\text { delirium, insomnia }\end{array}$ \\
\hline Beta-blocker & Rebound, recurrence & $\begin{array}{l}\text { Angina, hypertension, acute } \\
\text { coronary syndrome, tachycardia }\end{array}$ \\
\hline Corticosteroid & $\begin{array}{l}\text { Withdrawal, rebound, recurrence } \\
\text { if used long term }\end{array}$ & $\begin{array}{l}\text { Anorexia, hypotension, nausea, } \\
\text { suppression of the } \\
\text { hypothalamic-pituitary-adrenal } \\
\text { axis }\end{array}$ \\
\hline \multicolumn{3}{|c|}{$\begin{array}{l}\text { Decreased risk of } \\
\text { discontinuation syndrome }\end{array}$} \\
\hline ACE inhibitor & Recurrence & Heart failure, hypertension \\
\hline Antipsychotic & $\begin{array}{l}\text { Withdrawal, recurrence: } \\
\text { - When used for behavioural and } \\
\text { psychiatric symptoms of } \\
\text { dementia, taper dose with goal } \\
\text { to stop drug every } 3 \text { mo or more } \\
\text { if clinically appropriate (taper by } \\
25 \% \text { every } 1-2 \text { wk) } \\
\text { - Some behaviours decline as } \\
\text { disease worsens }\end{array}$ & $\begin{array}{l}\text { Dyskinesias, insomnia, nausea, } \\
\text { restlessness }\end{array}$ \\
\hline Anticholinergic & Withdrawal & $\begin{array}{l}\text { Anxiety, nausea, vomiting, } \\
\text { headaches, dizziness }\end{array}$ \\
\hline Digoxin & $\begin{array}{l}\text { Recurrence: patients can usually be } \\
\text { followed for signs and symptoms } \\
\text { of heart failure and medication } \\
\text { restarted as needed }\end{array}$ & Heart failure, tachycardia \\
\hline Diuretic & Recurrence & $\begin{array}{l}\text { Heart failure, hypertension, } \\
\text { edema }\end{array}$ \\
\hline Narcotic analgesia & $\begin{array}{l}\text { Withdrawal: if medication used } \\
\text { long term, tapering will decrease } \\
\text { risk of physical withdrawal }\end{array}$ & $\begin{array}{l}\text { Abdominal cramping, anxiety, } \\
\text { chills, diaphoresis, diarrhea, } \\
\text { insomnia }\end{array}$ \\
\hline
\end{tabular}


the process for cessation, and attitudes of family and physicians about the deprescribing process. Not surprisingly, patients' beliefs that the prescribed medication was doing something or was "better than doing nothing" presented barriers to stopping the medication, whereas beliefs that the medication was no longer appropriate enabled cessation. Patients reported that ensuring the process for deprescribing was monitored, supported and suitably paced assisted discontinuation, as did good relationships with the physicians and support of family over the process.

Recognition of terminal illness is an important reason to review goals of care and medications. However, even when faced with a terminal illness, some patients will be concerned about stopping medications they have been taking for years, especially when a physician in the past has stressed its importance. One example may be stopping a medication for the primary prevention of cardiovascular disease, even though there is little evidence to support its use in individuals aged over 80 years and even less evidence in those aged over 90. A randomized controlled trial is currently under way to determine whether there is a difference in survival time and quality of life between patients with advanced life-limiting illness whose statins are discontinued and those whose statins are continued (ClinicalTrials.gov trial no. NCT01415934).

Medications commonly used in palliative and end-of-life care can have adverse effects such as confusion, drowsiness, constipation and fatigue. To optimize the use of these medications, it may be prudent to minimize the use of other medications that could potentially worsen these effects. For example, ferrous gluconate may no longer provide achievable benefit for anemia but may exacerbate constipation caused by opiates.

Paradoxically, stopping a medication with a previously unrecognized adverse effect can sometimes improve overall function and change the short-term outlook at end of life. Although not well described in the literature, many physicians caring for patients with end-stage heart failure have had the experience of patients rallying with short-term improvement when high doses of cardiac medications are stopped or decreased because of apparently imminent death.

These practical lessons reinforce the importance of understanding the current indication for each medication prescribed to an older patient and a readiness to review and deprescribe as appropriate.

\section{Unanswered questions}

Which approach to deprescribing is most effective in improving clinical outcomes? Most approaches seem to involve a pharmacist and pre- scriber. Available study interventions are too heterogenous or poorly described to permit comparisons between approaches.

How effective are medication reviews in improving patient-centred results such as quality of life? Most existing trials fail to measure outcomes such as improved functioning and are of too short a duration or too small a size to show significant clinical improvements with deprescribing.

Does primary prevention of cardiovascular disease at end of life improve quality of life? Studies looking at the role of statins in end-oflife care are underway.

\section{References}

1. Principles of prescribing for elderly people. BPJ 2008;11:10-3. Available: www.bpac.org.nz/BPJ/2008/February/prescribing .aspx (accessed 2014 Aug 20).

2. Medication use and the elderly (update 2000) [policy]. Ottawa: Canadian Medical Association; 2000. Available: http://policy base.cma.ca/dbtw-wpd/PolicyPDF/PD01-04.pdf (accessed 2014 Aug 20).

3. Montastruc JL, Montastruc F. Prescribe, but also know how to "deprescribe." Prescrire Int 2013;22:192.

4. Woodward M. Deprescribing: achieving better health outcomes for older people through reducing medications. J Pharm Pract Res 2003;33:323-8.

5. Cross C. Introducing deprescribing into culture of medication. CMAJ 2013; 185:E606.

6. Claxton AJ, Cramer J, Pierce C. A systematic review of the associations between dose regimens and medication compliance. Clin Ther 2001;23:1296-310.

7. Hamilton HJ, Gallagher PF, O'Mahony D. Inappropriate prescribing and adverse drug events in older people. BMC Geriatr 2009;9:5.

8. Tamura BK, Bell CL, Inaba M, et al. Outcomes of polypharmacy in nursing home residents. Clin Geriatr Med 2012;28:217-36.

9. Lai SW, Liao KF, Liao CC, et al. Polypharmacy correlates with increased risk for hip fracture in the elderly: a population-based study. Medicine (Baltimore) 2010;89:295-9.

10. Huang ES, Karter AJ, Danielson KK, et al. The association between the number of prescription medications and incident falls in a multi-ethnic population of adult type- 2 diabetes patients: the diabetes and aging study. J Gen Intern Med 2010;25:141-6.

11. Ramage-Morin PL. Medication use among senior Canadians. Health Rep 2009;20:37-44.

12. Rockwood K, Stadnyk K, MacKnight C, et al. A brief clinical instrument to classify frailty in elderly people. Lancet 1999; 353:205-6.

13. Gnjidic D, Le Couteur DG, Kouladjian L, et al. Deprescribing trials: methods to reduce polypharmacy and the impact on prescribing and clinical outcomes. Clin Geriatr Med 2012;28:237-53.

14. Tjia J, Velten SJ, Parsons C, et al. Studies to reduce unnecessary medication use in frail older adults: a systematic review. Drugs Aging 2013;30:285-307.

15. Steinman MA, Hanlon JT. Managing medications in clinically complex elders: "There's got to be a happy medium." JAMA 2010; 304:1592-601

16. Iyer S, Naganathan V, McLachlan AJ, et al. Medication withdrawal trials in people aged 65 years and older: a systematic review. Drugs Aging 2008;25:1021-31.

17. Koller K, Rockwood K. Frailty in older adults: implications for end-of-life care. Cleve Clin J Med 2013;80:168-74.

18. Gurwitz JH. The physics of geriatric pharmacotherapy: overcoming therapeutic inertia and momentum. Am J Med 2012;125:523-4.

19. Desai R, Williams CE, Greene SB, et al. Medication errors during patient transitions into nursing homes: characteristics and association with patient harm. Am J Geriatr Pharmacother 2011;9:413-22.

20. Gleason KM, McDaniel MR, Feinglass J, et al. Results of the Medications at Transitions and Clinical Handoffs (MATCH) study: an analysis of medication reconciliation errors and risk factors at hospital admission. J Gen Intern Med 2010;25:441-7.

21. Turner J, Singhal N, Bell J. Opportunities for depresribing statins in patients with poor cancer prognosis. J Palliat Med 2013;16:1328.

22. Boyd CM, Darer J, Boult C, et al. Clinical practice guidelines and quality of care for older patients with multiple comorbid diseases: implications for pay for performance. JAMA 2005;294: 716-24. 
23. Campbell AJ, Robertson MC, Gardner MM, et al. Psychotropic medication withdrawal and a home-based exercise program to prevent falls: a randomized, controlled trial. J Am Geriatr Soc 1999;47:850-3.

24. Salzman C, Fisher J, Nobel K, et al. Cognitive improvement following benzodiazepine discontinuation in elderly nursing home residents. Int J Geriatr Psychiatry 1992;7:89-93.

25. Chertkow H, Massoud F, Nasreddine Z, et al. Diagnosis and treatment of dementia: 3. Mild cognitive impairment and cognitive impairment without dementia. CMAJ 2008;178:1273-85.

26. James PA, Oparil S, Carter BL, et al. 2014 evidence-based guidelines for the management of blood pressure in adults: report from the panel members appointed to the Eighth Joint National Committee (JNC 8). JAMA 2014;311: 507-20.

27. Aronow WS, Fleg J, Pepine C, et al. ACCF/AHA 2011 expert consensus document on hypertension in the elderly: a report of the American College of Cardiology Foundation Task Force on Clinical Expert Consensus Documents. Circulation 2011;123:2434-506.

28. Canadian Diabetes Association Clinical Practice Guidelines Expert Committee. Canadian Diabetes Association 2013 clinical practice guidelines for the prevention and management of diabetes in Canada. Can J Diabetes 2013;3(Suppl 1):S1-211.

29. Tinetti ME, Doucette J, Claus E, et al. Risk factors for serious fall injury among community elderly persons. J Am Geriatr Soc 1995;43:1214-21.

30. Declercq T, Petrovic M, Azermai M, et al. Withdrawal versus continuation of chronic antipsychotic drugs for behavioural and psychological symptoms in older people with dementia. Cochrane Database Syst Rev 2013;(3):CD007726.

31. Patterson SM, Hughes C, Kerse N, et al. Interventions to improve the appropriate use of polypharmacy for older people. Cochrane Database Syst Rev 2012;(5):CD008165.

32. American Geriatrics Society 2012 Beers Criteria Update Expert Panel. American Geriatrics Society updated Beers Criteria for potentially inappropriate medication use in older adults. J Am Geriatr Soc 2012;60:616-31.

33. Tinetti ME, McAvay GJ, Fried TR. Health outcome priorities among competing cardiovascular, fall injury, and medication-related symptom outcomes. J Am Geriatr Soc 2008;56:1409-16.

34. Gallagher P, O'Mahony D. STOPP (screening tool of older persons' potentially inappropriate prescriptions): application to acutely ill elderly patients and comparison with Beers' criteria. Age Ageing 2008;37:673-9.

35. Gokula M, Holmes HM. Tools to reduce polypharmacy. Clin Geriatr Med 2012;28:323-41.

36. Barry PJ, Gallagher P, Ryan C, et al. START (screening tool to alert doctors to the right treatment) - an evidence-based screening tool to detect prescribing omissions in elderly patients. Age Ageing 2007;36:632-8.

37. Rudolph JL, Salow MJ, Angelini MC, et al. The anticholinergic risk scale and anticholinergic adverse effects in older persons. Arch Intern Med 2008; 168:508-13.

38. Haque R. ARMOR: a tool to evaluate polypharmacy in elderly persons. Ann Long-Term Care 2009;17:26-30.

39. Garfinkel D, Zur-Gil S, Ben-Israel J. The war against polypharmacy: a new cost-effective geriatric-palliative approach for improving drug therapy in disabled elderly people. Isr Med Assoc J 2007;9:430-4.

40. Drenth-van Maanen AC, van Marum RJ, Knol W, et al. Prescribing optimization method for improving prescribing in elderly patients receiving polypharmacy: results of application to case histories by general practitioners. Drugs Aging 2009;26:687-701.

41. Yourman LC, Lee SJ, Schonberg MA, et al. Prognostic indices for older adults: a systematic review. JAMA 2012;307:182-92.

42. Rockwood K. Frailty index predicts NH placement and death. CMAJ 2005; 173:489-95.

43. Tinetti ME, McAvay GJ, Chang SS, et al. Contribution of multiple chronic conditions to universal health outcomes. J Am Geriatr Soc 2011;59:1686-91.

44. Bain KT, Holmes HM, Beers MH, et al. Discontinuing medications: a novel approach for revising the prescribing stage of the medication-use process. J Am Geriatr Soc 2008;56:1946-52.

45. Scott IA, Gray L, Martin J, et al. Deciding when to stop: towards evidencebased deprescribing of drugs in older populations. Evid Based Med 2013;18: $121-4$.

46. Schuling J, Gebben H, Veehof LJ, et al. Deprescribing medication in very elderly patients with multimorbidity: the view of Dutch GPs. A qualitative study. BMC Fam Pract 2012;13:56.

47. Reeve E, Shakib S, Wiese M. Patient barriers to and enablers of deprescribing: a systematic review. Drugs Aging 2013;30:793-807.

Affiliations: Providence Care Centre, St. Mary's of the Lake Hospital Site; Division of Geriatrics, Department of Medicine, Faculty of Health Sciences, Queen's University, Kingston, Ont.

Contributors: Both authors contributed to the original concept of the work and acquired, analyzed and interpreted data and references. They drafted and revised the manuscript, approved the final submission and agreed to be guarantors of the work.

Acknowledgement: Karen Gagnon contributed to the design and conduct of the original literature search and assisted with acquiring abstracts and articles. 